\title{
Performance Prediction of a Small-Size Adiabatic Compressed-Air Energy Storage System
}

\author{
G. Manfrida ${ }^{1 *}$, R. Secchi ${ }^{2}$ \\ Università degli Studi di Firenze, Dipartimento di Ingegneria Industriale, Firenze, Italy \\ E-mail: ${ }^{1}$ giampaolo.manfrida@ unifi.it, ${ }^{2}$ riccardo.secchi@unifi.it
}

Received 23 October 2014, Revised 30 March 2015, Accepted 06 April 2015

\begin{abstract}
The problem of decentralized energy storage is of crucial importance for the development of renewable energy resources. In the first stage of their development, RES have relied on the possibility of connecting to the grid. However, with increased RES share, pressure is being put on the electrical grid system, resulting in the necessity of extensive load modulation of traditional plants (hydroelectric and fossil), and also on the development of large energy storage facilities (hydro-pumped, CAES, batteries,...). From the point of view of distributed energy systems, connected to smart grids, it is rather interesting to develop local energy storage systems, which can help to decrease the load on the grid infrastructure, possibly paving the way to complete off-grid operation.

The case study is a Small-Size Advanced Adiabatic Compressed Air Energy Storage (SS-AA-CAES), developed from existing components (compressors, heat exchangers, vessels, expander,...) and coupled to a local PV field. The system operates trying to separate pressure energy and heat, and promoting regenerative/recuperative use of this last with low-temperature thermal storage (hot water) to cover the necessary time lag. The system also represents a CHP solution, as the hot water recovered from compressor cooling is available for heating purposes. A thermodynamic model of the system was built, used for design, and a simulation covering system operation over one year was performed. The results show that the system could be recommended (possibly with the support of battery storage) for use in applications where complete off-grid operation is preferable, or where it is important to minimize the impact of the grid infrastructure, such as in natural parks and remote areas.
\end{abstract}

Keywords: Adiabatic CAES; small scale CAES; photovoltaic; energy storage.

\section{Introduction}

Because of the fluctuating character of renewable energy sources like solar energy, energy storage systems are required to store the instant electricity production surplus in Off-grid/Smart-grid systems. Compressed Air Energy Storage (CAES) systems have been presented in various configurations as one of the most promising energy storage technologies. CAES has been historically deployed for grid management applications such as load shaving, load following, load shifting and regulation. Convectional CAES use Off-peak energy to compress and store air in a reservoir, usually an air-tight underground storage cavern. Upon demand, stored air is released from the cavern, heated and expanded through a combustion turbine to create electrical energy. The first CAES plant with 290 MW capacity has been operating in Huntorf, Germany, since 1978 [1]. The Huntorf plant is a diabatic CAES plant: the thermal energy resulting from the compression process, needs to be dissipated to avoid deterioration of the cavern [2]. Convectional diabatic plants reach an input output electricity efficiency of about $50 \%$, but they still depend on the combustion of gas, because the released air must be heated prior to expansion. In an Adiabatic CAES instead, the thermal energy is stored and used to reheat the compressed air during the discharging process. In Advanced Adiabatic CAES technology the use of fuel is avoided: a Thermal Energy Storage (TES) is substituted to the combustion chamber and the recovered heat allows to increase the compressed air temperature before expansion, without any additional fuel consumption. Grazzini and Milazzo [3] optimized the air storage volume and designed a system layout with TES. Zhang et al. [4] used a thermodynamic model of a CAES system with TES to analyze the effect of TES on system efficiency. Jubeh and Najjar [5] compared the performance of adiabatic and conventional CAES systems showing that the first offers relatively higher energy storage efficiency.

Bullough et al. [6] proposed AA-CAES for the storage of intermittent wind energy source. Simmons et al. [7] have analyzed the technical characteristics of energy storage technologies and the costs and benefits associated with solar Photovoltaic (PV) generation combined with energy storage. They provide estimates of the incremental value of energy storage when combined with solar PV.

Proczka et al. [8] focused on the sizing of pressure vessels for Small Scale CAES application. They define SSCAES in the range of $10 \mathrm{kWh}-10 \mathrm{MWh}$, suggesting that man-made vessel are the best compressed air storage solution at this scale.

Few works have been published on SS-CAES systems for stand-alone off-grid photovoltaic modules. Villela et al. [9] proposed a system of this type for powering appliances and residential units in order to minimize the dependency on centralized power system grids, but they focused on designing and examining a single-stage, displacementbased, piston-driven, quasi-isothermal air compressor 
capable of operating at the same range of powers that correspond to the output of PV panels.

In this paper we propose a preliminary design and annual performance evaluation of a SS-AA-CAES coupled with a typical residential size Photovoltaic plant in Off-Grid operation. The performance of the system was evaluated by a simulation model developed with TRNSYS ${ }^{\circledR}$ and EES ${ }^{\circledR}$. The proposed system is actually a Combined Heat and Power Unit, because a considerable part of the thermal energy recovered on daily basis from the compression process is made available as heat, while the necessary fraction is regenerated before expansion to increase the electricity production. Moreover, pressure energy is used for displacing the cooling and heating water, so that auxiliary electricity consumptions are almost entirely canceled.

\section{System Description and Working Principle}

The general configuration of the system (shown in Figure 1) consist of the following main components:

1. Photovoltaic plant

2. Compressor $\mathrm{C} 1$

3. Compressor $\mathrm{C} 2$

4. Compressed Air Reservoir CAR1

5. Heat exchangers (HE1, HE2, HE3)

6. Expander EXP

7. Hot Water Reservoir HWR

8. Cold Water Reservoir CWR

The system has been designed to perform daily cycles of two operational phases: Storage Mode (SM) and Production Mode (PM).

\subsection{Storage Mode}

In the Storage Mode a stand-alone photovoltaic plant covers as first duty the instant power needs of the users. When excess power is available, a two-stage air compression process is activated in order to store the surplus energy as pressure energy. Ambient air is used as working fluid. The compression is split in two steps: the first air compressor (C1) is a commercial screw unit operated with variable-speed drive. $\mathrm{C} 1$ has a delivery pressure of 10 bar. The second air compressor (C2) is a high-pressure reciprocating unit (again with variable-speed drive) modified from a commercial air-cooled air compressor, with a delivery pressure of 200 bar (inlet pressure 10 bar).

After each compressor a water-cooled compact heat exchanger brings down the air temperature to $30^{\circ} \mathrm{C}$, which is the design temperature for the Compressed Air Storage (CAR1). The cooling water flowing in HE1 and HE2 is drawn form a sealed tank (Cold Water Reservoir, CWR) and flows to the thermal storage tank (Hot Water Reservoir, HWR). HE2 is a special-design post-cooler heat exchanger, working with high-pressure on the air side (200 bar). Pumps are not used for water displacement, making it possible to avoid any electricity consumption for pumps, and to improve the reliability of the system reducing the number of moving parts: moderate pressurization of either tank (CWR/HWR), and a top/bottom arrangement using the potential energy difference (depending on the system layout) are effectively used for water displacement among the tanks, using a negligible part of the stored air pressure energy. A system of pneumatic solenoid valves to manage tank aeration (A) and venting (V) is required.

The charging stops when the air storage pressure reaches 200 bar. The minimum operational discharge pressure of CAR1 is 10 bar. CAR1 is assembled using common commercial pressurized air cylinders, designed for a 200 bar working pressure.

\subsection{Production Mode}

In the Production mode the compressed air flowing from CAR1 passes through the heat exchanger HE3, increasing its temperature. The air pressure is adjusted (at an intermediate range, 10 to 40 bar) with the first pressure regulator (PR1) before the heat exchanger; this allows a good heat transfer performance without strict requirements and higher costs connected to high-pressure operation.

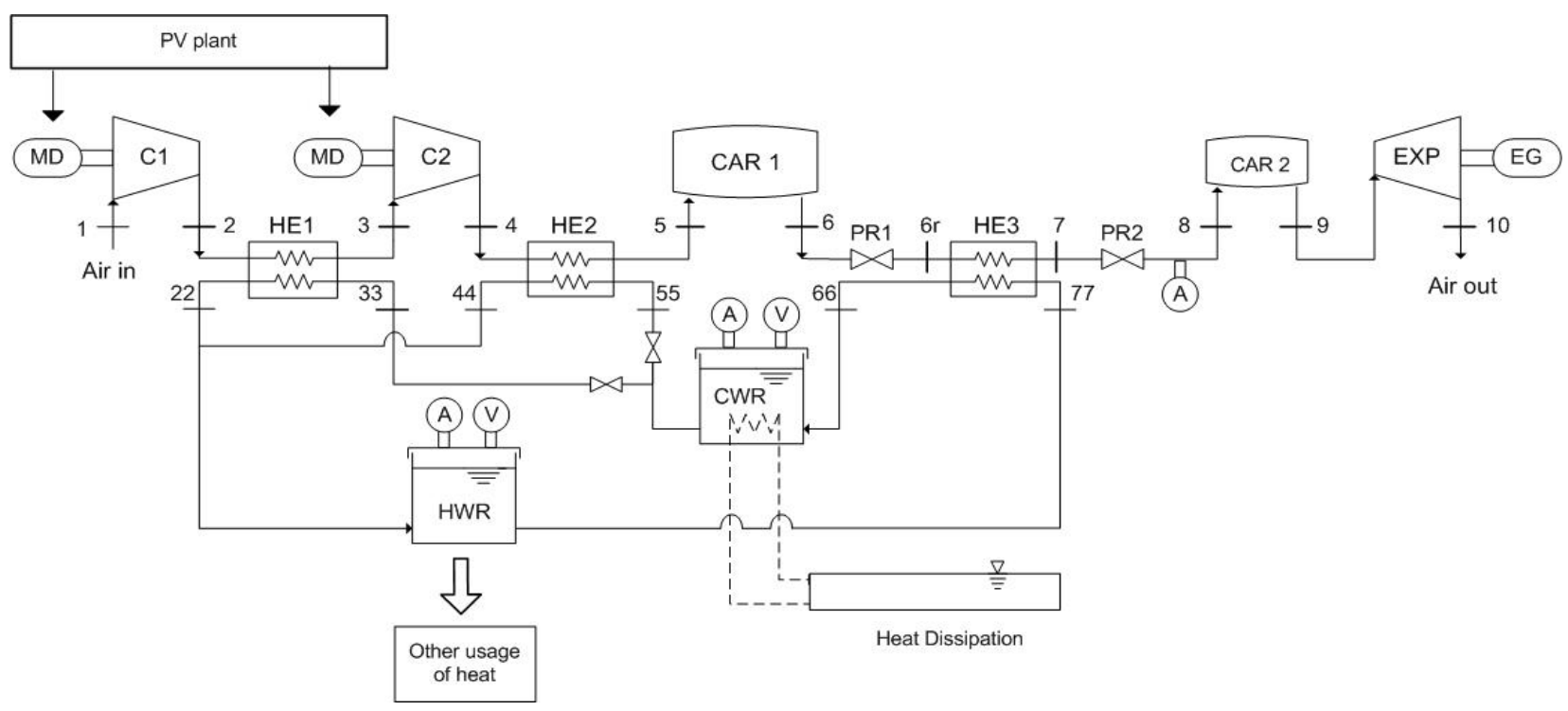

Figure. 1. System layout. 
The hot water stream flowing in HE3 is taken from the Hot Water Reservoir (HWR, always pressure-driven), where the thermal energy recovered from compressor intercooling has been previously stored. Then the air pressure is further reduced (PR2) to the design inlet pressure (4 bar) of the expander (EXP); this last is a piston-less rotary engine with a high efficiency (80\%) [10]. Always referring to Figure 1, CAR2 is a small low-pressure buffer storage upstream of the expander inlet. The expander is provided of an electrical generator, whose power output is used to cover the users electricity need in the evening off-sun period.

The expander exhaust air temperature must be restricted to $0^{\circ} \mathrm{C}$ due to possible issues arising from the condensation/freezing of moisture in the air during the expansion. The temperature reduction following expansion depends on the pressure ratio and on the machine efficiency. Therefore HE3 has the duty to increase the air temperature compensating the temperature reduction achieved in the expansion from 4 bar to atmospheric pressure, with a declared device isentropic efficiency of 0.8 . Because of the pressure reduction upstream of the expander, the compression ratio in SM (200) is much larger than the expansion ratio in PM (4). Storing air at high pressure is beneficial from the point of view of the vessel volume reduction, and allows an extensive range of operation (from 200 to 10 bar); however, this leads to a daily imbalance in the cooling and heating water needs, so that a large amount of thermal energy is available at the end of the day. The thermal energy is stored as high temperature water $\left(90^{\circ} \mathrm{C}\right)$, which attractive for several uses such as domestic heating systems, sanitary hot water production, or cold production by an absorption unit.

In order to close the daily operating cycle, the heat stored in HWR must be either used or dissipated to the environment (for example using a small evaporative pond, as suggested in Figure 1), in order to provide enough cold water $\left(30^{\circ} \mathrm{C}\right)$ in $\mathrm{CWR}$ for cooling down the next day compression phase.

\section{System Thermodynamic Model}

The photovoltaic plant provides intermittent power depending on solar radiation and users' electrical load profile; as a consequence the compressors are often working at partial load during the Storage Mode. For a given available power, the mass flow rate processed by $\mathrm{C} 1$ is calculated from the following equations (subscripts referred to Figure 1):

$$
\begin{aligned}
& \left(h_{2 i s}-h_{1}\right)=\frac{k}{k-1} \cdot R \cdot T_{1} \cdot\left[\left(\frac{p_{2}}{p_{1}}\right)^{\frac{k-1}{k}}-1\right] \\
& \dot{W}_{C 1}=\dot{m}_{C 1} \cdot \frac{\left(h_{2 i s}-h_{1}\right)}{\eta_{C 1}}
\end{aligned}
$$

The outlet temperature after the first compression results in:

$$
T_{2}=T_{1} \cdot\left[1+\left(\left(\frac{P_{2}}{P_{1}}\right)^{\frac{k-1}{k}}-1\right) / \eta_{C 1}\right]
$$

The second compressor processes the same flow rate ( $\dot{m}_{C 1}=\dot{m}_{C 2}$ ); equations similar to $1-3$ can be written in order to calculate the power consumption $\dot{W}_{C 2}$ and outlet temperature $T_{4}$ of $\mathrm{C} 2$. The discharge pressure of the second compressor $p_{4}$ depends on the air mass stored in CAR1, and thus also its power consumption. For a given available power, an iterative procedure is necessary to calculate $\dot{W}_{C 2}, p_{4}$ and $T_{4}$. The actual pressure $\left(p_{C A R I}\right)$ inside the storage is calculated from the ideal gas equation applied to the mass present in storage volume:

$$
p_{C A R 1}=m_{C A R 1} \cdot \frac{R \cdot T_{5}}{V_{C A R 1}}
$$

In Eq. $4 V_{C A R I}$ represents the cylinders physical volume. The value of $p_{4}$ is taken as the value of $p_{C A R I}$ at the previous time step, in a forward-marching solution approach.

With reference to the Production Mode, the expander must be operated with a fixed pressure of $p_{9}=4$ bars at inlet. The power output can be regulated, operating the expander (following the characteristic curve provided by the provider) with variable mass flow rate in order to follow the user electrical load. The expander mass flow rate can be computed by the following equations:

$$
\begin{aligned}
& \left(h_{9}-h_{10 i s}\right)=\frac{k}{k-1} \cdot R \cdot T_{9} \cdot\left[\left(\frac{p_{10}}{p_{9}}\right)^{\frac{k-1}{k}}-1\right] \\
& W_{E X P}=\eta_{E X P} \cdot m_{E X P} \cdot\left(h_{9}-h_{10 i s}\right) \\
& T_{10}=T_{9} \cdot\left[1+\eta_{E X P} \cdot\left(\left(\frac{p_{10}}{p_{9}}\right)^{\frac{k-1}{k}}-1\right)\right]
\end{aligned}
$$

The system air-water heat exchangers have been sized for fixed inlet and outlet temperature, depending on compressions output temperatures and expansion inlet temperature as shown in the following paragraph. The flow rates have been computed from the heat exchangers energy balance equations. As an example, for HE1 the energy balance can be written as follows:

$$
\dot{Q}_{H E 1}=\dot{m}_{C 1} \cdot\left(h_{2}-h_{3}\right)
$$

$$
\dot{Q}_{H E 1}=\dot{m}_{W H E 1} \cdot\left(h_{22}-h_{33}\right)
$$

Similar balances are set for HE2 and HE3. The sizing of the heat exchangers was performed using classical heat transfer correlations. All the preceding equations were implemented as EES modules; these last were used directly for evaluating the design conditions. They were then compiled separately to be used later (see Section 5) as original TRNSYS Types, using TRNSYS as the fundamental tool for examining off-design performance along one year.

\section{Preliminary DSesign}

The system preliminary design procedure was carried out starting from the assumptions on the off-sun period electricity production needs (peak power, period). Only 
commercially available components have been considered, with marginal modifications if needed for adaptation to this specific application. The sizing continued with the definition of the storages capacities and the compressors nominal power. The PV field peak power was not sized in advance, but it is object of a sensitivity analysis in order to check the annual load coverage trend varying the PV field extension.

Starting from the expander (PM operation), a $2 \mathrm{~kW}$ pneumatic Quasiturbine rotary expander has been selected according to the evening power demand of a small residential user. Table 1 shows the main features and limitations of the expander.

Table 1. Main Features of the Expander.

\begin{tabular}{lr}
\hline Maximum Intake pressure [bar] & 4 \\
Maximum Speed Revolution [rpm] & 600 \\
Displacement [cc] & 600 \\
Minimum Outlet Temperature $\left[{ }^{\circ} \mathrm{C}\right]$ & 0 \\
Nominal Power $[\mathrm{kW}]$ & 2 \\
Pressure-flow conversion efficiency [\%] & 80 \\
Nominal Flow rate $[\mathrm{kg} / \mathrm{s}]$ & 0.0174 \\
\hline
\end{tabular}

The physical volume of the compressed air storage $\left(V_{C A R}\right)$, has been sized to allow operation of the expander for 2 hours at nominal power, with a maximum storage pressure of 200 bar. The design calculations $\left(V_{C A R}=0.55\right.$ $\mathrm{m}^{3}$ ) resulted in a storage system consisting of 11 commercial cylinders, each one having a volume of 50 liters of air at 200 bar.

With reference to the Storage Mode, the compressors size was selected to fill the storage system in 8 hours. The main operating parameters of the compressors are shown in Table 2. A screw compressor is used for $\mathrm{C} 1$, able to provide a constant pressure over a reasonable range of rotational speeds $(25 \%-100 \%)$ according to manufacturer's data. The main variable changing with the actual working conditions (i.e. off-design) is thus the flow rate, provided that the operating range for the rotational speed is matched. A multi-stage high-pressure volumetric compressor was the choice for $\mathrm{C} 2$, which implies marginal modifications for intercooler and post-cooler heat recovery.

Table 2: Main Features of the Compressors.

\begin{tabular}{cc}
\hline \multicolumn{2}{c}{ Compressor 1 } \\
\hline Compression Ratio [-] & 10 \\
Nominal Power [kW] & 1.5 \\
\hline Compressor 2 \\
\hline Compression Ratio [-] & 20 \\
Nominal Power [kW] & 2.2 \\
\hline Compressors nominal flow rate $[\mathrm{kg} / \mathrm{s}]$ & 0.0044 \\
\hline
\end{tabular}

For heat exchangers sizing, air and water storage design temperatures have to be defined. The compressed air storage design temperature $\left(T_{C A R l}\right)$ is $30^{\circ} \mathrm{C}$. The Cold Water Storage Temperature $\left(T_{C W R}\right)$ is $20^{\circ} \mathrm{C}$, and the Hot Water Storage temperature $\left(T_{H W R}\right)$ is set at $90^{\circ} \mathrm{C}$. Therefore, the heat exchangers for compression cooling (HE1, HE2) were sized to achieve - at maximum load - the temperature profile resumed in Table3. According to Eq.7, and to constraints in the expander outlet temperature, the design temperature difference for HE3 is also shown in Table 3. During operation, the heat exchangers water flow rates vary following the air flow rate set by the variable speed compressors in Storage Mode; during Production Mode, the same happens following the expander flow rate, which is linked to the variable electrical power demand. For this preliminary design, the heat exchangers HE1, HE2, and HE3 were sized considering counter-current operation design using a Log Mean Temperature Difference approach. The heat transfer area was determined for design operating conditions using the heat transfer coefficient correlations provided by the EES ${ }^{\circledR}$ Heat Transfer and Fluid Flow library [11].

Table 3. Heat Exchangers Design Inlet and Outlet Temperatures.

\begin{tabular}{cccccc}
\hline & \multicolumn{2}{c}{ Air } & \multicolumn{2}{c}{ Water } & LMTD \\
\cline { 2 - 5 } & inlet & outlet & inlet & outlet & \\
\cline { 2 - 5 } & {$\left[{ }^{\circ} \mathrm{C}\right]$} & {$\left[{ }^{\circ} \mathrm{C}\right]$} & {$\left[{ }^{\circ} \mathrm{C}\right]$} & {$\left[{ }^{\circ} \mathrm{C}\right]$} & {$\left[{ }^{\circ} \mathrm{C}\right]$} \\
\hline HE1 & 626 & 30 & 20 & 90 & 132.1 \\
HE2 & 793 & 30 & 20 & 90 & 163.0 \\
HE3 & 30 & 85 & 90 & 40 & 7.2 \\
\hline
\end{tabular}

The capacity of the water storages was determined after calculating the cooling and heating water flow rates in the most demanding conditions for daily operation, resulting in $H W R$ Capacity $=$ CWR Capacity $=0.3 \mathrm{~m}^{3}$.

Two storage tanks (one of which is insulated) of the type normally used for solar thermal applications was employed. On a daily basis in design conditions, the usable thermal energy stored in HWR amounts to $72900 \mathrm{~kJ}$ (272 liters of water with a 20 to $90^{\circ} \mathrm{C}$ temperature difference).

\section{Dynamic Simulations and Performance Evaluation}

The annual performance of the system positioned in a specific geographical location was evaluated by a dynamic simulation model, developed with TRNSYS ${ }^{\circledR}[12]$. Pisa San Giusto was the Italian Location selected for the simulations of weather conditions (Solar Radiation, Ambient Temperature), considering the availability of extensive meteorological data in the TRNSYS ${ }^{\circledR}$ weather database. The simulation time-step was fixed at $1 \mathrm{~h}$. The model's structure is as follows:

a. Weather Data and Photovoltaic system: The TRNSYS ${ }^{\circledR}$ components related to weather conditions, photovoltaic panels and inverter, allow to obtain the value of the Maximum Power Point Photovoltaic power for each time step at the selected geographical location. PV Module performance data were taken from the SunPower Web Site [13] and are representative of a typical Mono-Crystal PV module. The electrical data have been used in the fourparameter equivalent circuit model on which the TRNSYS Type 94 is based [12]. The inverter efficiency was assumed to be 0.9 .

b. Thermodynamic Calculations: The thermodynamic modeling of fluid conditions in SM and PM has been carried out in $\operatorname{EES}^{\circledR}[11]$ using the energy balance equations (1-7). Data are exchanged between TRNSYS and the EES executable at each simulation time step.

c. System Control: A set of TRNSYS components allows to check the power generated by the Photovoltaic array, defining the portion that is used to meet the instantaneous 
user power demand and the surplus to be stored as pressure and thermal energy.

d. User Load Profile: A simplified annual electrical load profile has been obtained using an annual averaged daily profile for each day of the year (Figure 2). Integrating the load profile over the simulated year results in an annual electricity consumption of $6424 \mathrm{kWh} \quad\left(E_{L P}\right)$. This corresponds approximately to the consumption of a twofamily Italian dwelling, as can be deduced from the results of the Italian "MICENE" project, which monitored in 2004 the electricity consumption of 110 Italian households (various Regions, house dimensions, inhabitants) [14, 15]. The collected data indicated a national average annual consumption of $3230 \mathrm{kWh}$ per household.

e. Setting the operating phases: Using the TRNSYS ${ }^{\circledR}$ components called "Forcing function" [12], it is possible to limit the duration of the two operation phases.

Considering the Load Profile shown in Figure 2, and its compatibility with the daily solar radiation profile, the maximum daily SM duration was set to 12 hours (8-20), and the maximum daily PM operation duration was set to 2 hours (20-22). Control signals enable and stop the operation phases also depending on stop conditions based on the CAR1 actual pressure control (Max/Min pressure). The Compressors are turned off when the design storage pressure $\left(P_{C A R I}=200 \mathrm{bar}\right)$ is reached, while the discharge of CAR1 is arrested when the residual pressure approaches the imposed lower limit (10 bar).

The aim of the dynamic simulations was to assess the annual energy production (electricity and thermal energy) and the percentage of load coverage achieved by the system. A sensitivity analysis has also been run in order to check the effects of PV size variation on the performance parameters.

The main performance indexes are defined as follows:

- $G L C$ (Global Load Coverage): Ratio between the Total Annual Electricity generated by the system and the Total Annual Electricity consumption according to the load profile.

$$
G L C=\frac{\mathrm{E}_{\mathrm{TOT}}}{\mathrm{E}_{\mathrm{LP}}}
$$

- $\quad$ PVLC (Photovoltaic Load Coverage): Ratio between the Annual Electricity generated by the PV field directly used to meet the load and the Total Annual Electricity consumption according to the load profile.

$$
P V L C=\frac{\mathrm{E}_{\mathrm{LPV}}}{\mathrm{E}_{\mathrm{LP}}}
$$

- ELC (Expander Load Coverage): Ratio between the Annual Electricity generated by the Expander and the Total Annual Electricity consumption according to the load profile.

$$
E L C=\frac{\mathrm{E}_{\mathrm{EXP}}}{\mathrm{E}_{\mathrm{LP}}}
$$

The following parameters have also been computed for the annual simulations:

- $\eta_{E L}\left(\right.$ Electrical Efficiency) $: \eta_{E L}=\frac{\mathrm{E}_{\mathrm{EXP}}}{\mathrm{E}_{\mathrm{COMP}}}$

- $P E S_{R}$ (Relative Primary Energy Saving): This Index is usually proposed for the performance evaluation of Combined Heat and Power Plants [16]. Actually, the proposed system, integrated with a PV field, can be seen as equivalent to a CHP plant, whose input is the renewable solar energy resource. The $\mathrm{PES}_{\mathrm{R}}$ is at present used in European Legislation to compare the cogeneration plant with separate production of electricity and heat.

$$
P E S_{R}=1-\frac{\left(\frac{\mathrm{E}_{\mathrm{EXP}}}{\eta_{E L}}\right)}{\left(\frac{E_{E X P}}{\eta_{G R I D}}+\frac{E_{T H}}{\eta_{S T H}}\right)}
$$

where:

- $\eta_{\text {GRID }}=0.4, \quad$ Efficiency of standard electricity distribution grid.

$-\eta_{S T H}=0.9$, Efficiency of standard thermal energy production system.

- $E_{T H}=$ annual available thermal energy.

- $\eta_{P S U}$ (Primary Source Utilization Efficiency): Ratio between the annual electricity used by the system for both meeting the actual users power demand $\left(\mathrm{E}_{\mathrm{LPV}}\right)$ and powering the compressors $\left(\mathrm{E}_{\mathrm{COMP}}\right)$, and the annual Electricity generated by the PV field.

$$
\eta_{P S U}=\frac{\mathrm{E}_{\mathrm{LPV}}+\mathrm{E}_{\mathrm{COMP}}}{\mathrm{E}_{\mathrm{PV}}}
$$

\section{Results of the Simulations}

Annual simulations were performed changing the photovoltaic field size; a peak power ranging from $1.3 \mathrm{~kW}$ to $8 \mathrm{~kW}$ was considered. Table 4 shows the annual energy production parameters introduced in paragraph 5 resulting from the simulations. The annual thermal energy available $\left(E_{T H}\right)$ shown in Table 4 can be compared with the annual average heat consumption of a typical household, in order to verify the theoretical coverage of the thermal needs. However it must be pointed out that the thermal energy is only available as a result of a previous Storage Mode (SM) operation. In days with lack of surplus energy from renewable sources, the system does not start the compression phase, and thermal energy cannot be stored. 


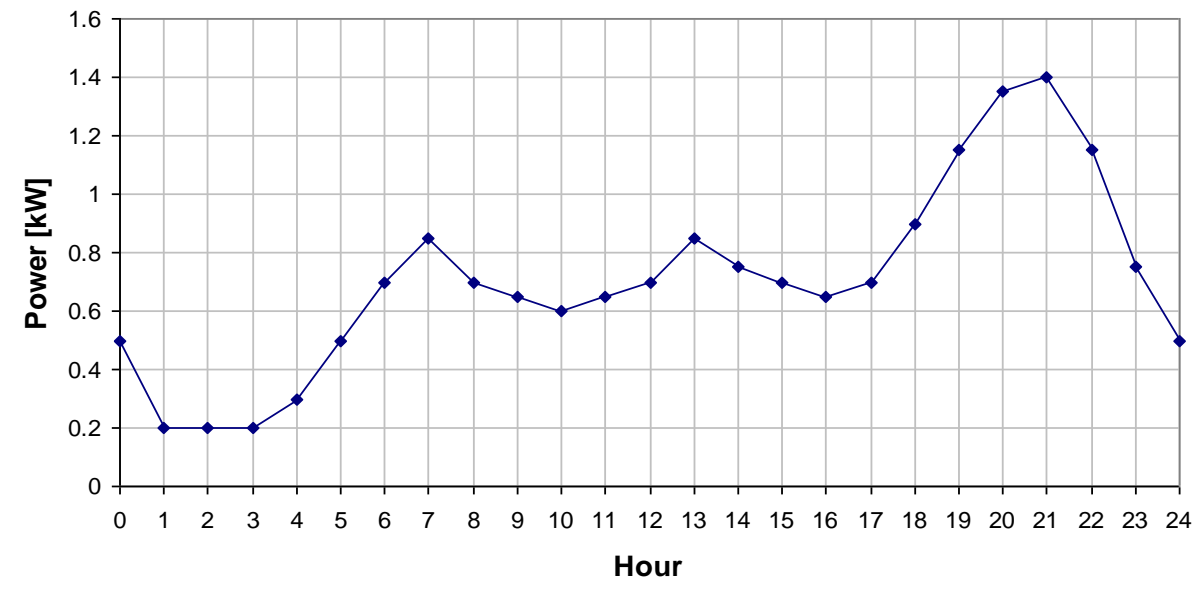

Figure.2. Annual averaged daily electrical load profile for a typical Italian household.

On the other hand, when enough surplus energy is available to start the compression phase, thermal energy is usable even before the end of the SM. It should be reminded that much less heat is needed to preheat the air in HE3, compared with the amount ideally recoverable during compressions. In real operation, it is expected that the amount of thermal energy actually available $\mathrm{E}_{\mathrm{TH}}$ will be reduced by the thermal losses in the compressor and in the heat exchangers, leading to a smaller need of heat dissipation to close the thermodynamic cycle.

An annual average domestic hot water $\left(50^{\circ} \mathrm{C}\right)$ consumption of 60 liters/capita/day is a reasonable assumption for DHW requirements for high-occupancy residences $[17,18]$. The annual thermal energy consumption for DHW can be thus estimated in $635 \mathrm{kWh} /$ year. According to the simulation results, a $2.6 \mathrm{kWp} \mathrm{PV}$ leads to a theoretical coverage of DHW needs for a 3-people household.

Table 5 shows the performance indexes introduced in paragraph 5, computed using a theoretical annual electricity consumption of $6424 \mathrm{kWh}$ (integration of profile in Figure 2). The Global Load Coverage increases with the PV size and tends asymptotically to the limit imposed by the compressed air storage size: further renewable surplus energy cannot be stored. The numerical value of the limit computed for GLC (about 0.6) also depends on the theoretical annual electricity consumption set.

Due to the PM design duration (which in turn determines the compressed air storage capacity), the load coverage in the night hours (22 p.m. to 8 a.m.) cannot be completely satisfied, affecting the results of the GLC. Modified version of the performance indexes were thus computed referring to the load required in the design operation time band ( 8 a.m. to 10 p.m.). The modified indexes (indicated with subscript MOD) are also shown in Table 5. A $5.3 \mathrm{kWp}$ PV size allows to cover $75 \%$ of load profile in the $8 \mathrm{a} . \mathrm{m}$. to $10 \mathrm{p} . \mathrm{m}$. band for annual simulations.

Figure 3 shows the percentage of load coverage in different time bands. The load coverage in the band 8 p.m. to $10 \mathrm{p} . \mathrm{m}$. is only provided by the expander (through the storage system), whereas the load coverage in the band 8 a.m. to 8 p.m. is only met by the PV plant. The load profile in PM period is almost completely covered (85\%) with a 8 $\mathrm{kWp}$ PV plant size, which means that the PV plant provides surplus power to drive the compressors at nominal power for a large part of the year.

Table 4: Annual Energy Production for Different PV size.

\begin{tabular}{ccccccc}
\hline $\boldsymbol{P V}$ Size $(\boldsymbol{k W p})$ & $\boldsymbol{P V}$ area $\left(\boldsymbol{m}^{2}\right)$ & $\boldsymbol{E}_{\boldsymbol{E X P}}(\boldsymbol{k W h})$ & $\boldsymbol{E}_{\boldsymbol{L P V}}(\boldsymbol{k W h})$ & $\boldsymbol{E}_{\boldsymbol{C} O M P}(\boldsymbol{k W h})$ & $\boldsymbol{E}_{\text {TOT }}(\boldsymbol{k W h})$ & $\boldsymbol{E}_{\text {TH }}(\boldsymbol{G J})$ \\
\hline 1.3 & 6.4 & 21.6 & 1724.0 & 129.4 & 1794.5 & 0.3 \\
2.6 & 12.8 & 313.2 & 2270.2 & 2278.4 & 2608.1 & 6.0 \\
4.0 & 19.2 & 560.7 & 2493.6 & 4282.8 & 3064.7 & 11.6 \\
5.3 & 25.6 & 682.6 & 2620.2 & 5306.1 & 3301.1 & 14.1 \\
6.7 & 32.0 & 747.3 & 2704.5 & 5866.8 & 3439.2 & 15.4 \\
8.0 & 38.4 & 788.8 & 2763.7 & 6208.9 & 3525.2 & 16.2 \\
\hline
\end{tabular}

Table 5: Performance Indexes for Different PV size.

\begin{tabular}{ccccccccccc}
\hline $\boldsymbol{P V}$ SIZE $(\boldsymbol{k W p})$ & $\boldsymbol{G L C}$ & $\boldsymbol{G L C} \boldsymbol{C}_{\text {MOD }}$ & $\boldsymbol{P V L C}$ & $\boldsymbol{P V L C} \boldsymbol{C}_{\text {MOD }}$ & $\boldsymbol{E L C}$ & $\boldsymbol{E L C} \boldsymbol{C}_{M O D}$ & $\eta_{E L}$ & $\boldsymbol{P E S}_{\boldsymbol{R}}$ & $\eta_{P S U}$ \\
\hline 1.3 & 0.28 & 0.37 & 0.276 & 0.366 & 0.003 & 0.005 & 0.17 & 0.19 & 0.886 \\
2.6 & 0.41 & 0.55 & 0.364 & 0.482 & 0.050 & 0.067 & 0.14 & 0.14 & 0.979 \\
4.0 & 0.49 & 0.65 & 0.400 & 0.530 & 0.090 & 0.119 & 0.13 & 0.14 & 0.941 \\
5.3 & 0.53 & 0.70 & 0.420 & 0.556 & 0.109 & 0.145 & 0.13 & 0.12 & 0.813 \\
6.7 & 0.55 & 0.73 & 0.433 & 0.574 & 0.120 & 0.159 & 0.13 & 0.11 & 0.696 \\
8.0 & 0.57 & 0.75 & 0.443 & 0.587 & 0.126 & 0.168 & 0.13 & 0.11 & 0.604 \\
\hline
\end{tabular}




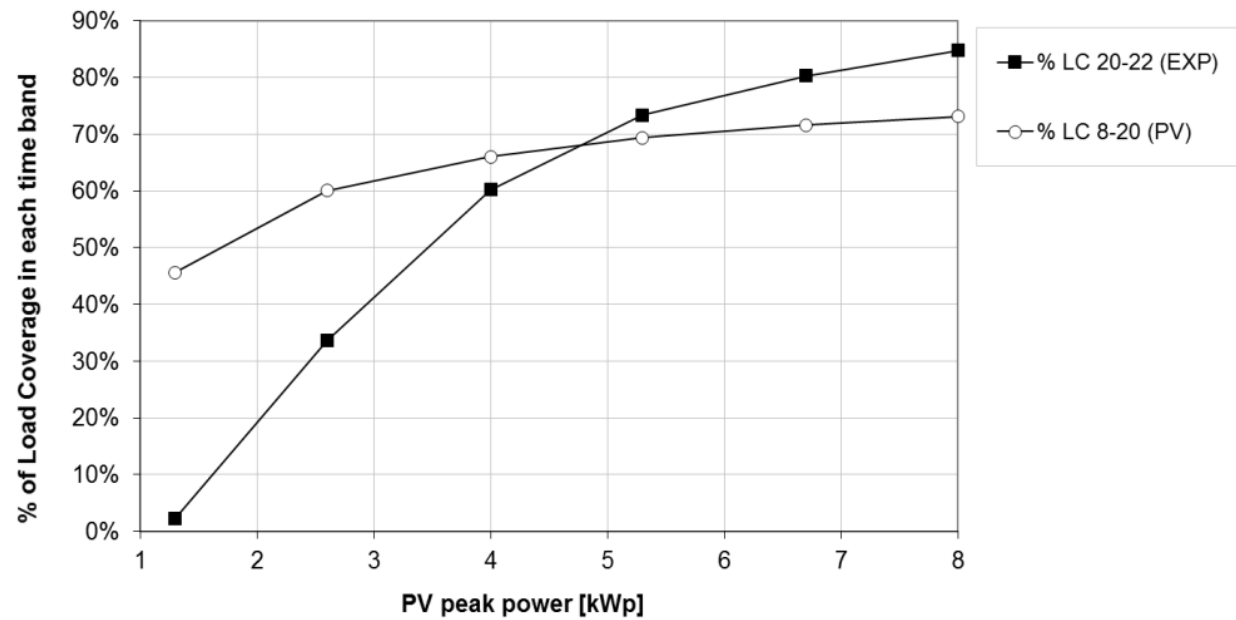

Figure 2. Percentage of load coverage in different time bands for different PV sizes.

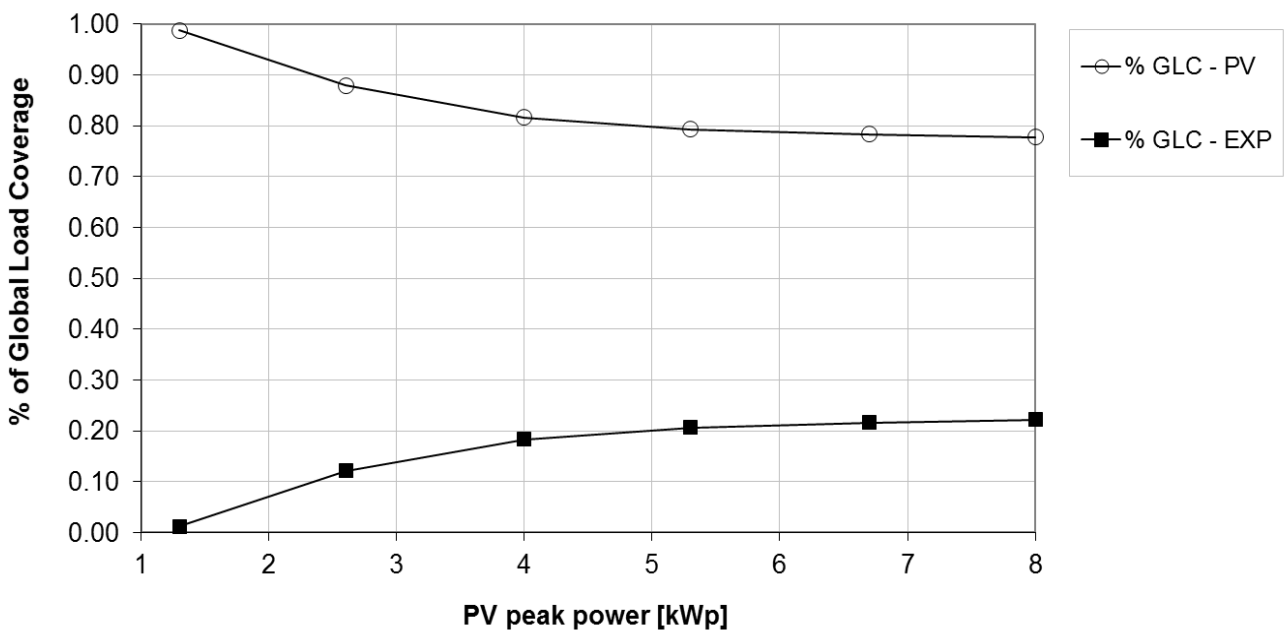

Figure 4. Percentage of global electrical load coverage for different PV sizes.

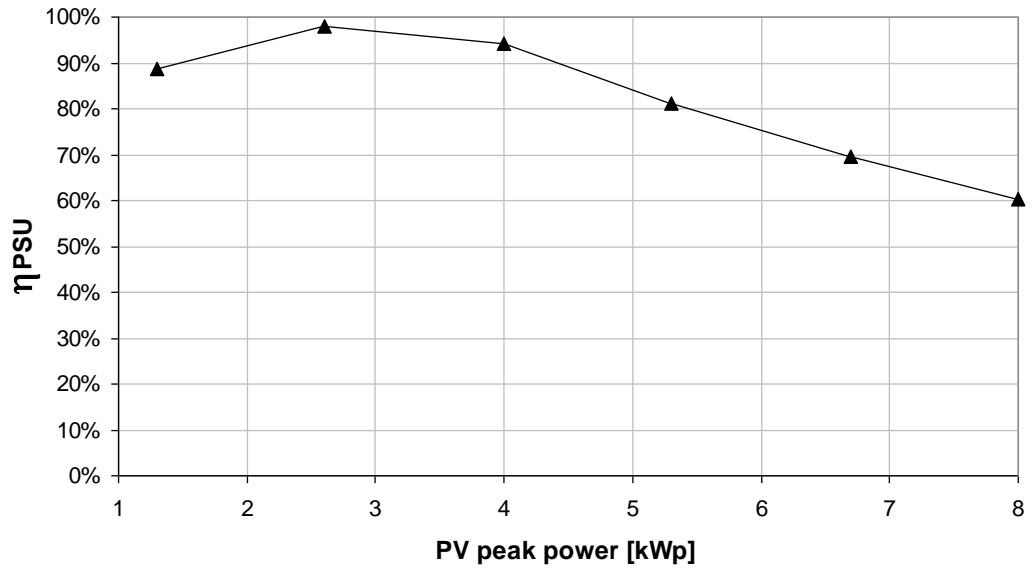

Figure 5. Primary source utilization efficiency for different PV sizes. 
Figure 4 shows the subdivision of the Global Load Coverage into the relative contributions from the PV and expander. The fraction of global load covered by the expander and the PV tends to $20 \%$ and $80 \%$, respectively. These values comply with the fractions of theoretical energy needs to be met in the different design time bands ((8 a.m. to 8 p.m.); (8 p.m. to 10 p.m.).) computed from the load profile (Figure 2).

Comparing the PV energy production with the total energy used by the system (including both meeting the actual users power demand and powering the compressors), the efficiency of primary source utilization in an Off-grid context can be checked. Figure 5 shows the trend of the primary source utilization efficiency $\left(\eta_{\text {PSU }}\right)$ with variable PV size. From the point of view of utilization of the primary resource, the optimal size of the PV system is 2.6 $\mathrm{kW}$. As it was expected, larger PV plants lead to a higher amount of waste energy in an Off-grid context. The storage system coupled with a $5.3 \mathrm{kWp}$ PV plant uses about $80 \%$ of the PV annual energy production. Obviously in this context the main objective is to have the greatest possible coverage of the energy needs, consistent with a photovoltaic field area applicable to the domestic environment. Achieving higher electricity demand coverages, however leads to less efficiently exploit the primary resource, that is, the solar radiation.

\section{Conclusions}

A SS-AA-CAES coupled with a typical residential-size photovoltaic plant has been studied. The system has been proposed as a renewable energy storage solution in an OffGrid/Smart-Grid context. A preliminary sizing of the system has been performed selecting commercially available components (Compressors, Heat exchangers, Expander, Air Storage, Water Storage). A sensitivity analysis regarding the effects of different PV size was run, calculating the relevant indicators.

The annual simulations results showed that the proposed storage system would lead to an electrical load coverage approaching $60 \%$ in Off-grid operation. This value is increased to $75 \%$ if referred to the load profile in the design operation period (8-22).

The Load coverage function in the time band (20-22) is only fulfilled by the expander (hence the storage system). The load profile in this period is almost completely covered (85\%) with a $8 \mathrm{kWp} \mathrm{PV} \mathrm{plant} \mathrm{size,} \mathrm{meaning} \mathrm{that} \mathrm{the} \mathrm{PV}$ plant would provide surplus power to drive the compressors at nominal power for a large part of the year.

Increasing the PV size leads to higher power available during the SM, which cannot be stored and should be dumped in an Off-grid context (or, sold to the grid - if available).

The electrical efficiency of the storage system is quite low (11-17\% varying the PV size); however the $P E S_{R}$ shows that the system is advantageous if compared with separate electrical and thermal energy production from nonrenewable sources (0.11-0.19). A large amount of thermal energy is available on a daily basis, because of the considerable difference between the compression ratio (200) and the expansion ratio (4), which was set by the commercially available expander. Considering an annual average domestic hot water $\left(50^{\circ} \mathrm{C}\right)$ consumption of 60 liters/capita/day, a $2.6 \mathrm{kWp}$ PV coupled to the proposed SSAA-CAES system should allow to cover the annual DHW needs for a 3 people household.
The system here analyzed is currently being assembled, with marginal adjustments. Some relevant improvements resulted from the current study, some of which have already been implemented in the prototype:

- Simplification of the intercooled compressor train, using directly an intercooled volumetric compressor, with substitution of the air intercoolers with air/water heat exchangers

- Suppression of the expensive heat recovery aftercooler, operating at extreme air pressure.

- Selection of a larger expander, capable also of variable-inlet-pressure operation

- A limited support of battery storage should be added, in order to avoid switching on the expander for limited electric loads.

As a final issue of the present simulation study, it is possible to conclude that the system could be recommended for applications where complete off-grid operation is foreseen, such as natural parks and remote areas.

\section{Acknowledgments}

The Authors are indebted to Mr. Enrico Pertici for helping to develop the TRNSYS model of the system in his graduation project work. This work has been performed as a model/design preliminary study for a demonstration project financed by Regione Toscana, POR-FESR 2012, to La Fabbrica del Sole SCRL, Arezzo, Italy, under the frame of a cooperation agreement between FDS and University of Firenze.

\begin{tabular}{ll}
\multicolumn{2}{l}{ Nomenclature } \\
$E$ & Energy, $\mathrm{MJ}$ \\
$\dot{m}$ & mass flow rate, $\mathrm{kg} / \mathrm{s}$ \\
$h$ & enthalpy, $\mathrm{J} / \mathrm{kg}$ \\
$k$ & specific heat ratio \\
$p$ & pressure, bar \\
$P M$ & Production Mode \\
$\dot{Q}$ & heat rate, $\mathrm{kW}$ \\
$R$ & specific gas constant, $\mathrm{J} /(\mathrm{kgK})$ \\
$S$ & entropy, $\mathrm{J} /(\mathrm{kg} \mathrm{K})$ \\
$S M$ & Storage Mode \\
$T$ & temperature, ${ }^{\circ} \mathrm{C}$ \\
$V$ & volume \\
$\dot{W}$ & power, $\mathrm{kW}$
\end{tabular}

\section{Greek Symbols}

$\eta \quad$ efficiency

$\begin{array}{ll}\text { Subscripts and Superscripts } \\ 1 & \text { first compressor inlet } \\ 2 & \text { first compressor outlet } \\ 4 & \text { second compressor outlet } \\ 5 & \text { compressed air storage inlet } \\ 9 & \text { expander inlet } \\ 10 & \text { expander outlet } \\ \text { a } & \text { ambient } \\ \text { C1 } & \text { first compressor } \\ \text { C2 } & \text { second compressor } \\ \text { CAR1 } & \text { Main compressed air storage } \\ \text { EXP } & \text { expander } \\ \text { IS } & \text { isentropic } \\ \text { LP } & \text { load profile } \\ \text { WHE1 } & \text { water in the first heat exchanger }\end{array}$




\section{References}

[1] M. Raju, S.K. Khaitan "Modeling and simulation of compressed air storage in caverns: A case study of the Huntorf plant”, Applied Energy, 89, 474-481, 2012.

[2] N.Hartmann, O. Vöhringer, C. Kruck, L. Eltrop "Simulation and analysis of different adiabatic Compressed Air Energy Storage plant configurations", Applied Energy, 93, 541-548, 2012

[3] G. Grazzini, A. Milazzo "Thermodynamic analysis of CAES/TES systems for renewable energy plants", Renewable Energy 33, 1998-2006, 2008.

[4] Y. Zhang, K. Yang, X. Li, J. Xu "The thermodynamic effect of thermal energy storage on compressed air energy storage system", Renewable Energy, 50, 227-235, 2013.

[5] N.M. Jubeh, Y.S.H. Najjar "Green solution for power generation by adoption of adiabatic CAES system", Applied Thermal Engineering, 44, 85-89, 2012.

[6] C. Bullough, C. Gatzen, C. Jakiel, M. Koller, A. Nowi, S., Zunft "Advanced Adiabatic Compressed Air Energy Storage for the Integration of Wind Energy", Proceedings of the European Wind Energy Conference, London, UK, 2004.

[7] J. Simmons, A. Barnhart, S. Reynolds, S. Young-Jun "Study of Compressed Air Energy Storage with Grid and Photovoltaic Energy Generation", The Arizona Research Institute for Solar Energy (AzRISE) - APS Final Draft Report, Compressed Air Energy Storage and Photovoltaics Study, University of Arizona, August 2010.

[8] J.J. Proczka, K. Muralidharan, D. Villela, J.H. Simmons, G. Frantziskonis "Guidelines for the pressure and efficient sizing of pressure vessels for compressed air energy storage", Energy Conversion and Management, 65, 597-605, 2013.

[9] D. Villela, V.V. Kasinathan, S. De Valle, M. Alvarez, G. Frantziskonis, P. Deymier, K. Muralidharan "Compressed-Air Energy Storage Systems For StandAlone Off-Grid Photovoltaic Modules", Proceedings of the 35th IEEE Photovoltaic Specialists Conference (PVSC), 962-967, ISBN: 978-1-4244-5890-5, 2010.

[10] Quasiturbine website: http://quasiturbine.promci.qc.ca/EProductQT75SCPne umatic.htm (Accessed on September 26th, 2014)
[11] EES, Engineering Equation Solver

[12] TRNSYS $®$ Software Mathematical Reference

[13] SunPower website:

http://us.sunpower.com/sites/sunpower/files/medialibrary/data-sheets/ds-x21-series-335-345-residentialsolar-panels-datasheet.pdf (Accessed on March 25th, 2014)

[14] F. Di Andrea, A. Danese "MICENE - Misure dei consumi di energia elettrica nel settore domestico Risultati delle campagne di rilevamento dei consumi elettrici presso 110 abitazioni in Italia”, eERG, enduse Efficiency Research Group, Dipartimento di Energetica Politecnico di Milano, project founded by Ministero dell'Ambiente e della Tutela del Territorio, 2004

[15] B. Di Pietra, "Performance Assessment of Residential Cogeneration Systems in different Italian climatic zones". Report of Subtask C of FC+COGEN-SIM The Simulation of Building-Integrated Fuel Cell and Other Cogeneration System. Annex 42 of the International Energy Agency Energy Conservation in Buildings and Community Systems Programme, 2007.

[16] M.F. Torchio "Energy-Exergy, Environmental and Economic Criteria in Combined Heat and Power (CHP) Plants: Indexes for the Evaluation of the Cogeneration Potential", Energies, 6, 2686-2708, 2013; doi:10.3390/en6052686.

[17] J.C. Evartsa, L.G. Swan "Domestitic hot water consumption estimates for solar thermal system sizing", Energy and Buildings, 58, 58-65, 2013.

[18] Energy Saving Trust "Measurement of Domestic Hot Water Consumption in Dwellings", Report prepared by the Energy Monitoring Company in conjunction with and on behalf of the Energy Saving Trust with funding and support of the Sustainable Energy Policy Division of the Department for Environment, Food and Rural Affairs, Crown Copyright, 2008. Accessible at:

https://www.gov.uk/government/uploads/system/uploa ds/attachment_data/file/48188/3147-measuredomestic-hot-water-consump.pdf (September 26th, 2014) 